\title{
DESENVOLVIMENTO DE METODOLOGIA DE CONTROLE DE VAZÃO DE AR PRIMÁRIO PARA COMBUSTÃO E DE RESFRIAMENTO DAS QUEIMADORES NA SAMARCO MINERAÇÃO*
}

\section{Resumo}

\author{
Maycon Athayde ${ }^{1}$
} Sergio Fernando Nunes ${ }^{1}$ Luiz Claudio da Silva ${ }^{2}$

A Samarco Mineração utiliza combustível gasoso para geração de energia térmica para o endurecimento pelotas de minério de ferro. O balanceamento térmico do forno ocorre através do controle das malhas de instrumentação que são compostas por válvulas de controle, sensores de temperatura, queimadores e sistema de suprimento de Gás Natural Industrial (GNI) para a combustão. A combustão é realizada por meio de queimadores, que são alimentados por uma mistura gasosa de GNI e Ar Atmosférico, ambos a temperatura ambiente. A função do GNI é fornecer a sua máxima capacidade energética para a produção de calor. Já o Ar atmosférico é resfriar o queimador, e estabilizar a chama dentro da câmara e ar primário de combustão. No entanto excesso de ar é fator determinante para eficiência de combustão, pois controla os produtos da queima, entre eles a temperatura. Um grande excesso de ar é indesejável, pois reduz a temperatura da chama, e aumenta as perdas de calor devido à entalpia dos gases.

Palavras-chave: Ar atmosférico; Combustão; Gás natural.

\section{DEVELOPMENT OF METHODOLOGY FOR CONTROL OF AIR FLOW FOR IMMEDIATE FIRE AND COOLING OF BURNERS IN MINING SAMARCO}

\begin{abstract}
The Samarco uses gaseous fuel for thermal power generation for pellet induration of iron ore. Heat the oven balancing occurs through control of instrumentation that meshes consist of control valves, temperature sensors, burners and supply of Natural Gas Industrial System (GNI) for combustion. The combustion is carried out by means of burners which are powered by a gas mixture of atmospheric air and GNI, both at room temperature. The function of GNI is to provide the maximum power capacity for heat production. Since the atmospheric air, and the burner cool and stabilize the flame in the primary chamber and the combustion air. However excess air is critical for combustion efficiency factor because it controls the products of combustion, including the temperature. A large excess of air is undesirable because it reduces the flame temperature and increases the heat loss due to enthalpy of the gas.
\end{abstract}

Keywords: Atmospheric air; Combustion; Natural gas.

1 Engenheiro Metalurgista, MSc, Eng., Samarco Mineração, Anchieta, ES, Brasil.

2 Técnico de Instrumentação, Samarco Mineração, Anchieta, ES, Brasil.

* Contribuição técnica ao 44 - Seminário de Redução de Minério de Ferro e Matérias-primas, 15 Simpósio Brasileiro de Minério de Ferro e $2^{\circ}$ Simpósio Brasileiro de Aglomeração de Minério de Ferro, 15 a 18 de setembro de 2014, Belo Horizonte, MG, Brasil. 


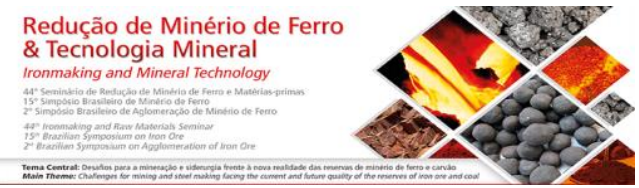

\section{INTRODUÇÃO}

O forno de endurecimento é uma das fases do processo de pelotização, onde as pelotas de minério de ferro são submetidas a um rigoroso procedimento de tratamento térmico que garante resistência mecânica adequada para as etapas de manuseio, transporte e utilização nos reatores de redução de nossos clientes.

O balanceamento térmico do forno ocorre através do controle das malhas de instrumentação que são compostas por válvulas de controle, sensores de temperatura, queimadores e sistema de suprimento de Gás Natural Industrial (GNI) para a combustão. A combustão é realizada por meio de queimadores, que são alimentados por uma mistura gasosa de GNI e ar atmosférico, ambos à temperatura ambiente. A função do GNI é fornecer a sua máxima capacidade energética para a produção de calor. Já o ar atmosférico é resfriar o queimador, e estabilizar a chama dentro da câmara e ar primário de combustão.

No entanto, excesso de ar é fator determinante para eficiência de combustão, pois controla os produtos da queima, entre eles a temperatura. Um grande excesso de ar é indesejável, pois reduz a temperatura da chama e aumenta as perdas de calor devido à entalpia dos gases.

Com a troca do gás para o óleo o sistema de refrigeração dos queimadores passou a ter um papel secundário em relação ao óleo, onde era necessário ainda atomizar o combustível.

$\mathrm{O}$ ar frio injetado no forno gera perdas térmicas e aumenta o consumo energético que, por sua vez, também aumenta o consumo de gás natural. O gás natural representa $54,5 \%$ da matriz de custos com insumos para pelotização. A figura 1 mostra a variação da série temporal de um processo extremamente instável sugerindo ótimas oportunidades de melhoria. Nele podemos observar que a amplitude dos dados amostrais chegou a $12 \%$ do valor do valor médio.

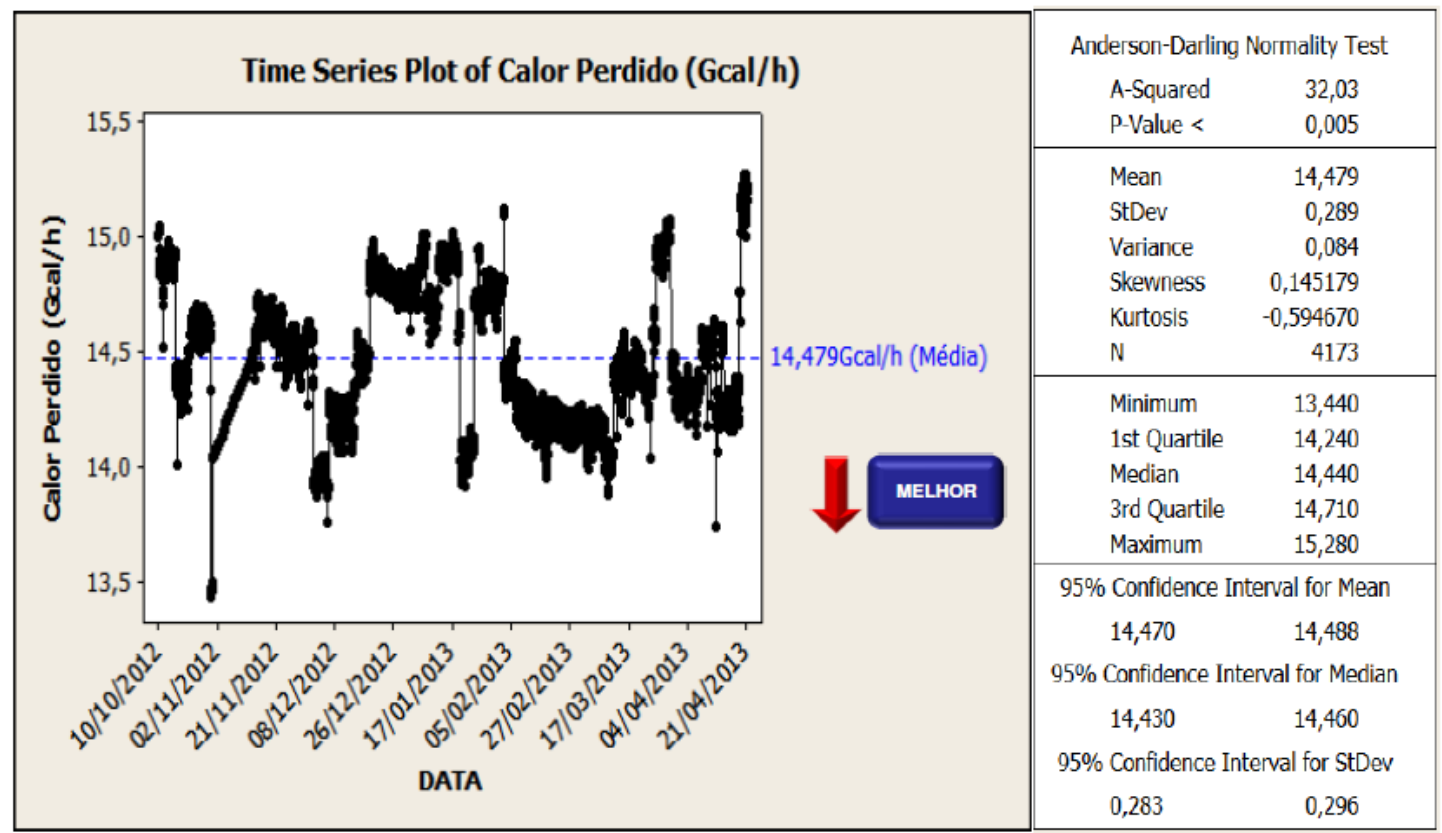

Figura 1- Variação do Calor perdido pelo sistema de Ar de resfriamento das camisas dos queimadores

* Contribuição técnica ao 44ํ Seminário de Redução de Minério de Ferro e Matérias-primas, $15^{\circ}$ Simpósio Brasileiro de Minério de Ferro e $2^{\circ}$ Simpósio Brasileiro de Aglomeração de Minério de Ferro, 15 a 18 de setembro de 2014, Belo Horizonte, MG, Brasil. 
A matriz de custos dos insumos da pelotização no ano de 2012 mostra que $54,5 \%$ é o gás natural industrial que é utilizado para a produção de pelotas. Como mostra a Figura 2.

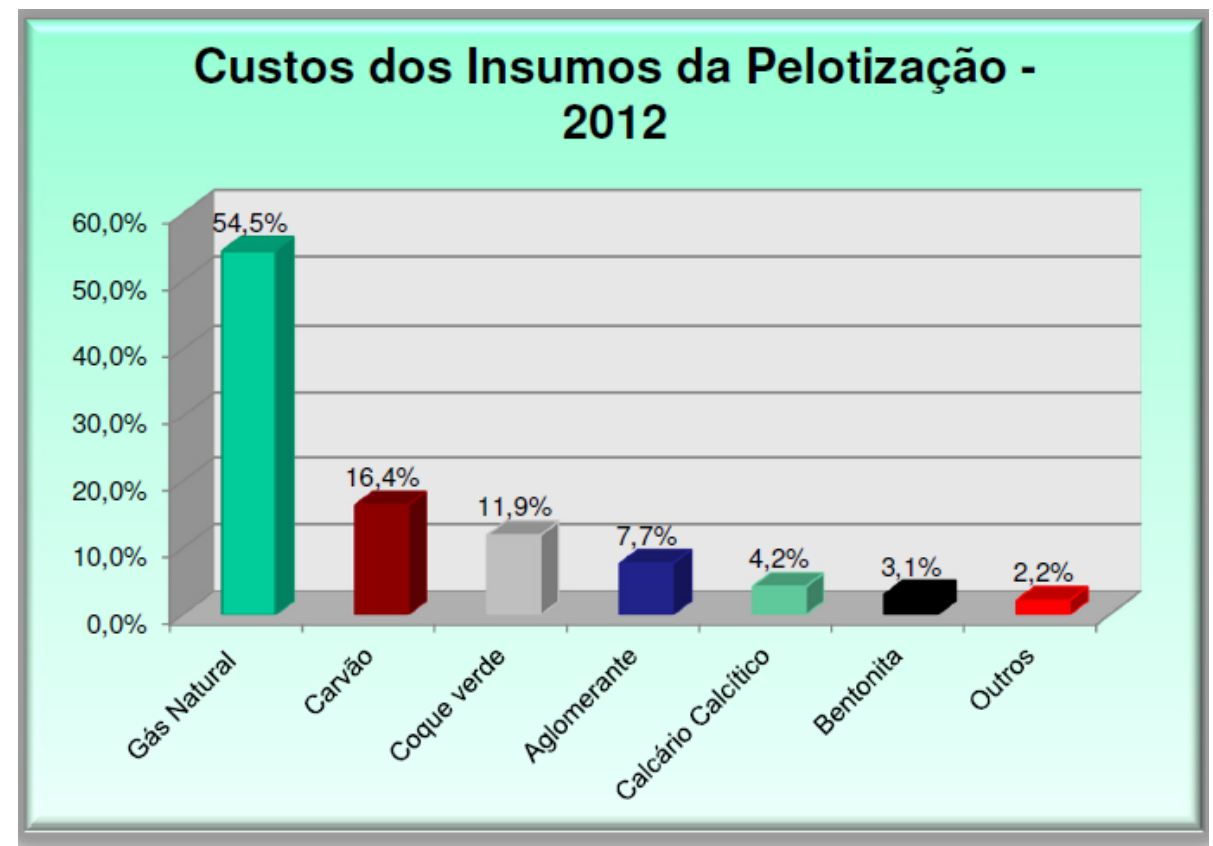

Figura 2 - Custos dos Insumos da Pelotização em 2012.

O projeto foi desenvolvido na etapa de endurecimento das pelotas. Essa etapa é composta por quatro fases: secagem ascendente, secagem descendente, queima e resfriamento. Eis a tabela 1 que explicita as expectativas e as necessidades dos clientes:

Tabela 1 - Expectativas e necessidades dos clientes.

\begin{tabular}{|c|c|}
\hline \multicolumn{1}{|c|}{ VoC (Voz do Cliente) } & Questões chave \\
\hline $\begin{array}{c}\text { Melhorar a eficiência térmica do forno para o } \\
\text { endurecimento das pelotas no forno. }\end{array}$ & \begin{tabular}{c} 
Reduzindo perda térmicas no forno \\
\hline Não impactar na resistência mecânica dos \\
queimadores.
\end{tabular} \\
\hline Não Impactar na temperatura do refratário. & $\begin{array}{c}\text { Controlar a temperatura na camisa do } \\
\text { queimador. }\end{array}$ \\
\hline Preservar as características da chama. & $\begin{array}{c}\text { Controlar a temperatura na câmara de } \\
\text { combustão. }\end{array}$ \\
\hline
\end{tabular}

O projeto em estudo está delimitado apenas às perdas térmicas que são provocadas pelo sistema de combustão durante a injeção de ar frio para resfriamento das camisas dos queimadores do forno da Usina 3 que é esquematizado na figura 3.

* Contribuição técnica ao 44 Seminário de Redução de Minério de Ferro e Matérias-primas, $15^{\circ}$ Simpósio Brasileiro de Minério de Ferro e $2^{\circ}$ Simpósio Brasileiro de Aglomeração de Minério de Ferro, 15 a 18 de setembro de 2014, Belo Horizonte, MG, Brasil. 


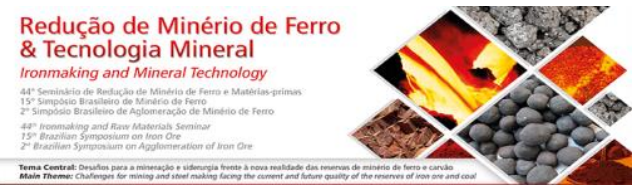

Sistema de Ar de Resfriamento das camisas dos queimadores do Forno da Usina III

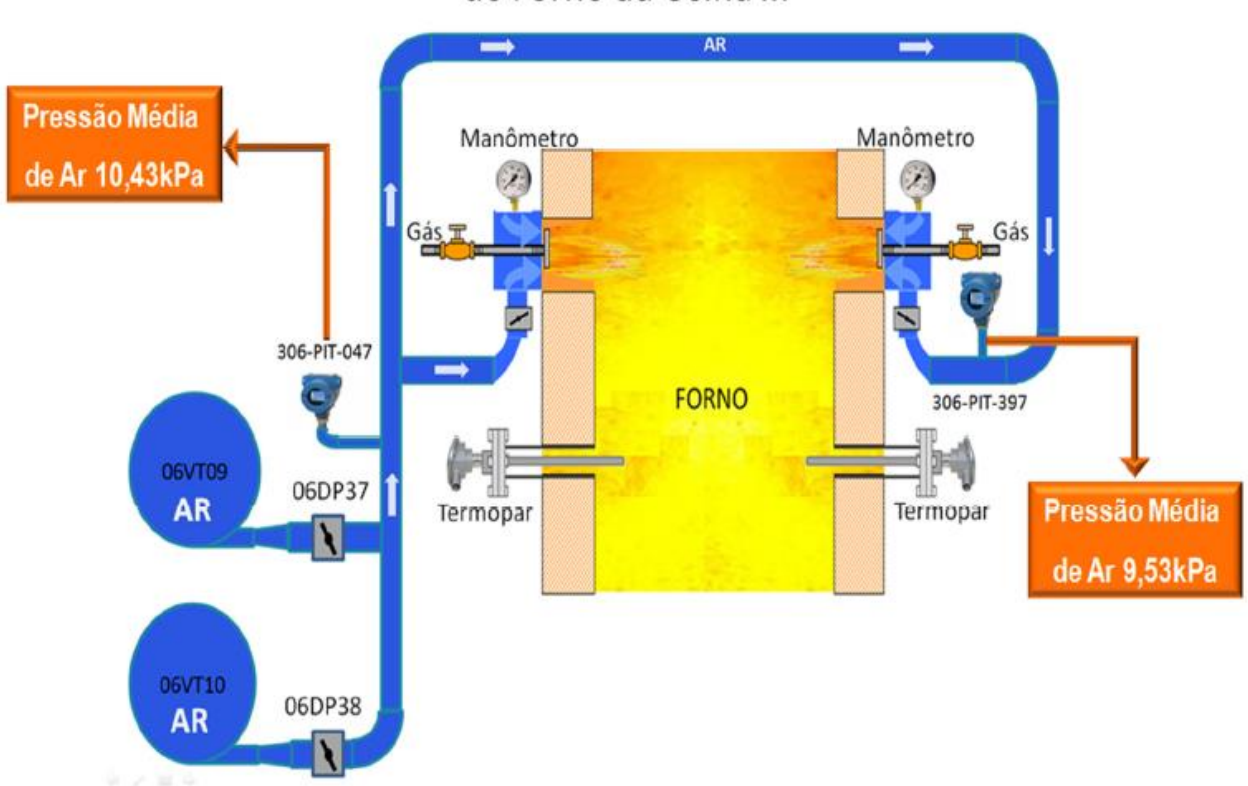

Figura 3 - Sistema de ar de resfriamento das camisas dos queimadores.

Como não temos uma medição direta para as perdas térmicas e este indicador é em função da pressão do ar frio que é injetado no forno por meio dos ventiladores de pressurização, utilizaremos essa variável para medição do problema. Sendo assim, os cálculos das perdas térmicas apresentados ao decorrer do projeto, serão estimados através da pressão do ar frio. A origem dos dados de pressão de ar de resfriamento das camisas dos queimadores pode ser obtida através do PIMS e do sistema Supervisório de controle delta V.

\section{OBJETIVO}

Reduzir as perdas térmicas, pelo sistema de combustão, da Usina III de $14,5 \mathrm{Gcal} / \mathrm{h}$ para $13,8 \mathrm{Gcal} / \mathrm{h}$ até 31 de Janeiro de 2014.

É desejável que através da redução das perdas térmicas no forno reduza também o consumo energético do formo.

\section{MATERIAIS E MÉTODOS}

O instrumento que fornece o valor da pressão do ar de resfriamento possui um plano de manutenção e calibração periódica. Para calibração do transmissor de pressão é utilizado um manômetro digital rastreado e calibrado por um laboratório acreditado pelo INMETRO. A medição de pressão possui redundância de transmissores, na mesma linha de ar que apresenta a mesma tendência. O comportamento histórico do indicador mostra que não existe controle de pressão de ar de resfriamento.

Nota-se que os dados amostrais da pressão de ar de resfriamento das camisas dos queimadores apresentam uma média de $10,44 \mathrm{kPa}$, com desvio de 0,379. Percebe-se também que o valor máximo registrado foi de $11,42 \mathrm{kPa}$ e mínimo de $9,50 \mathrm{kPa}$, sendo que não há presença de outlier e os dados não possuem uma distribuição normal.

* Contribuição técnica ao 44 - Seminário de Redução de Minério de Ferro e Matérias-primas, 15 Simpósio Brasileiro de Minério de Ferro e $2^{\circ}$ Simpósio Brasileiro de Aglomeração de Minério de Ferro, 15 a 18 de setembro de 2014, Belo Horizonte, MG, Brasil. 

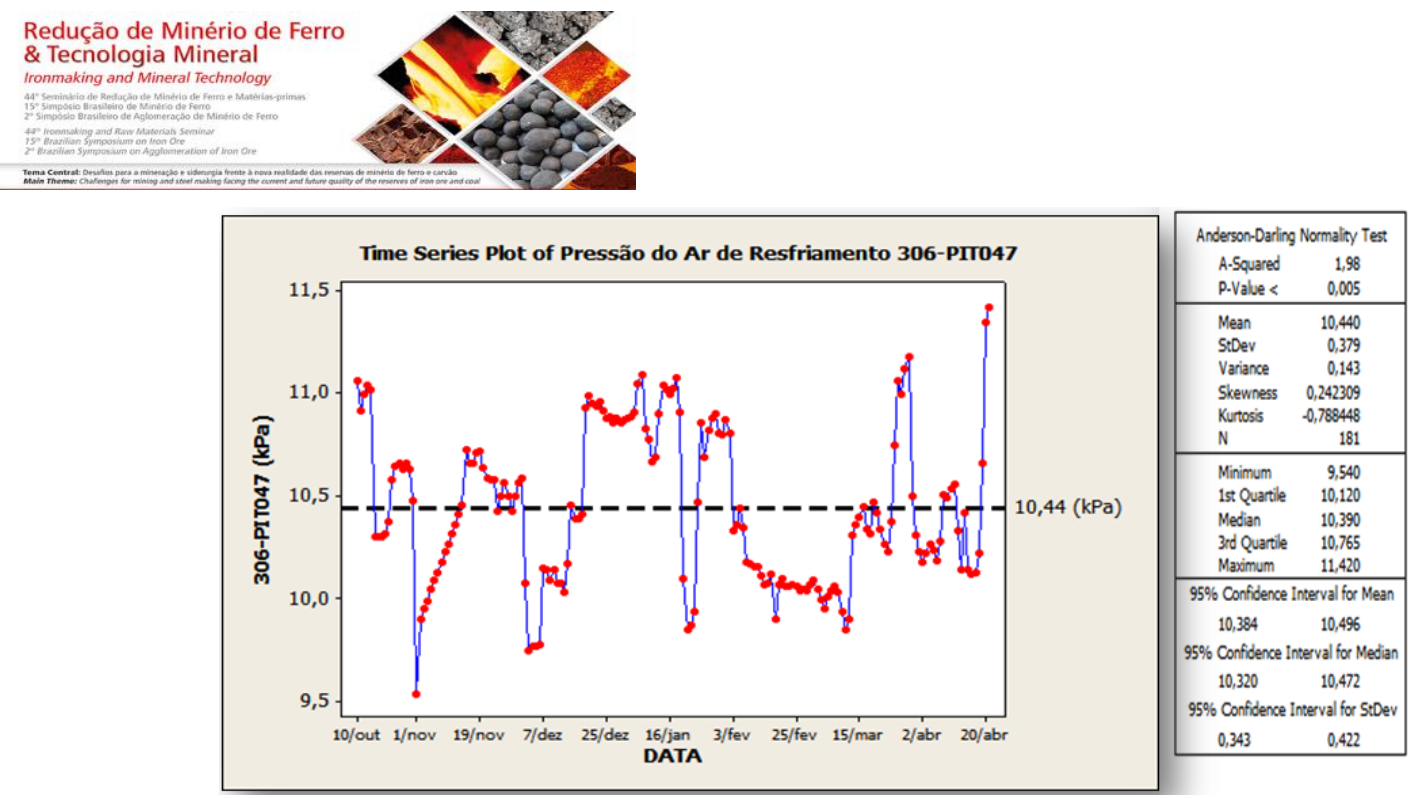

Figura 4 - Comportamento histórico do indicador do projeto.

Foi criada uma estratégia de análise para os experimentos em escala industrial que serão realizados com o objetivo de avaliar o a relação entre diversos níveis de pressão de ar de resfriamento e a qualidade de chama, temperatura no refratário, temperatura na camisa do queimador e a vazão de ar de resfriamento. Foi realizado um único brainstorming com toda a equipe de projeto contemplando os dois ventiladores, uma vez que a equipe concluiu que as causas que influenciam os dois equipamentos são similares. Foram detectadas 19 causas possíveis. Após isso foi elaborado um diagrama de causa e efeito a fim de identificar as causas fundamentais que estão listadas na tabela 2.

Tabela 2 - Causas fundamentais que influenciam na variação da pressão de Ar.

\begin{tabular}{|l|l|}
\hline X'S & \multicolumn{1}{|c|}{ CAUSAS } \\
\hline X1 & Falta de treinamento \\
\hline X2 & Erro de indicação da pressão na tela do operador \\
\hline X3 & Falta de padronização para o controle do Ar \\
\hline X4 & Metodologia desconhecida \\
\hline X5 & Temperatura do Ar \\
\hline X6 & Ventiladores super dimensionados \\
\hline X7 & Falta de controle dos dampers dos Vts 06VT009 e 06VT010 \\
\hline X8 & Ventiadores sem controle de velocidade \\
\hline X9 & Filtros de ar dos ventiladores fora de especificação \\
\hline X10 & Instrumentos de controle descalibrados \\
\hline X11 & Temperatura da camisa do Queimador \\
\hline X12 & Temperatura do Refratário \\
\hline X13 & Temperatura da Chama \\
\hline X14 & Qualidade da chama \\
\hline X15 & Especificação técnica do queimador \\
\hline X16 & Delta P no transporte do ar muito alto \\
\hline X17 & Emissão de NoX, C0, CO2 \\
\hline X18 & Falta indicação local \\
\hline X19 & Erro de indicação no manômetro \\
\hline
\end{tabular}

Através do GUT foi possível encontrar os X's vitais que tem influência significativa sobre o problema. Os X's com suas relevâncias são mostrados na tabela 3. Nesta etapa conseguimos identificar que as 6 causas mais relevantes, podem ser consideradas causas raízes.

* Contribuição técnica ao 44ํ Seminário de Redução de Minério de Ferro e Matérias-primas,

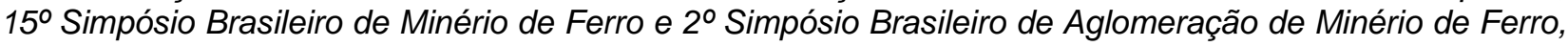
15 a 18 de setembro de 2014, Belo Horizonte, MG, Brasil. 
Tabela 3 - Causas raízes com suas relevâncias

\begin{tabular}{|c|c|c|c|c|c|}
\hline Entradas & Causas & Gravidade & Urgéncia & Tendència & Prionidade \\
\hline $\mathrm{x} 3$ & Falta de padronização para o controle do Ar & 4 & 5 & 4 & 80 \\
\hline$x 7$ & Falta de controle dos dampers dos Vts 06VT009 e 06VT010 & 4 & 5 & 4 & 80 \\
\hline $\mathrm{X} 10$ & Instrumentos de controle descalibrados & 4 & 5 & 4 & 80 \\
\hline $\mathrm{X} 1$ & Falta de treinamento & 4 & 4 & 4 & 64 \\
\hline $\mathrm{X} 15$ & Especificação técnica do queimador & 4 & 4 & 4 & 64 \\
\hline$X 4$ & Metodologia desconhecida & 4 & 3 & 4 & 48 \\
\hline$\overline{X 8}$ & Ventadores sem controle de velocidade & 3 & 3 & 5 & 45 \\
\hline $\mathrm{X6}$ & Ventiladores super dimensionados & 3 & 3 & 3 & 27 \\
\hline $\mathrm{Xg}$ & Filtros de ar dos ventiladores fora de especificação & 3 & 3 & 3 & 27 \\
\hline $\mathrm{X} 11$ & Temperatura da camisa do Queimador & 3 & 3 & 3 & 27 \\
\hline $\mathrm{X} 19$ & Erro de indicaç̧̃o no manómetro & 3 & 3 & 3 & 27 \\
\hline$X_{2}$ & Erro de indicaçăo da pressão na tela do operador & 3 & 3 & 3 & 27 \\
\hline $\mathrm{X} 16$ & Dellta $P$ no transporte do ar munto alto & 3 & 2 & 3 & 18 \\
\hline $\mathrm{X} 12$ & Temperatura đo Reflratário & 3 & 2 & 3 & 18 \\
\hline $\mathrm{X} 13$ & Tremperatura da Chama & 3 & 2 & 3 & 18 \\
\hline $\mathrm{X} 14$ & Qualidade da chama & 2 & 3 & 3 & 18 \\
\hline $\mathbf{X 5}$ & Temperatura do As & 3 & 2 & 2 & 12 \\
\hline $\mathrm{X} 17$ & Emissão de $\mathrm{Nox}, \mathrm{CO}, \mathrm{CO} 2$ & 3 & 2 & 2 & 12 \\
\hline $\mathrm{X} 18$ & Falta indicaçăo local & 2 & 2 & 1 & 4 \\
\hline & & & & & \\
\hline & & & & & \\
\hline
\end{tabular}

\section{RESULTADOS E DISCUSSÕES}

Através dos experimentos industriais foi possível analisar qual é a pressão ideal para ser utilizada no resfriamento das camisas dos queimadores sem causar impactos na qualidade da chama e na temperatura os refratários das câmaras de combustão. A principal ação a ser estabelecida é o controle da abertura dos dampers é suficiente para 0 alcance das metas. As ações listadas pela equipe são suficientes para o alcance das metas. A tabela 4 mostra se as causas potenciais podem ser confirmadas como causas raízes.

Tabela 4 - Confirmação das causas raízes.

\begin{tabular}{|c|c|c|c|c|c|c|c|}
\hline \multirow[b]{2}{*}{ Ref. } & \multirow[b]{2}{*}{ Hipótese } & \multirow[b]{2}{*}{$\begin{array}{l}\text { Análise - teste } \\
\text { realizado }\end{array}$} & \multicolumn{3}{|c|}{ Resultado } & \multirow[b]{2}{*}{$\begin{array}{l}\text { Causa } \\
\text { raiz? }\end{array}$} & \multirow[b]{2}{*}{ Comentários } \\
\hline & & & 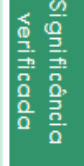 & $\begin{array}{l}\frac{6}{3} \\
\frac{9}{3} \\
\frac{0}{0} \\
\frac{0}{0} \\
\frac{0}{3} \\
\frac{0}{3}\end{array}$ & 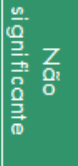 & & \\
\hline 1 & $\begin{array}{l}\text { Teste de temperatura na } \\
\text { camisa do queimador. }\end{array}$ & Teste de Regressão & $\mathrm{x}$ & & & $\begin{array}{l}\text { Pressão } \\
\text { de Ar }\end{array}$ & $\begin{array}{l}\text { O valor da pressão de ar esta diretamente ligada } \\
\text { com a variação de temperatura das camisas dos } \\
\text { queimadores. }\end{array}$ \\
\hline 2 & $\begin{array}{l}\text { Teste de temperatura sup. } \\
\text { Câmara de combustão. }\end{array}$ & Teste de Regressão & $\mathrm{x}$ & & & $\begin{array}{c}\text { Pressão } \\
\text { de Ar }\end{array}$ & $\begin{array}{l}\text { O valor da pressão de ar esta diretamente ligada } \\
\text { com a variação de temperatura da parte superior } \\
\text { das câmaras de combustão. }\end{array}$ \\
\hline 3 & $\begin{array}{l}\text { Teste de temperatura inf. } \\
\text { Câmara de combustão. }\end{array}$ & Teste de Regressão & $\mathrm{X}$ & & & $\begin{array}{c}\text { Pressão } \\
\text { de } \mathrm{Ar}\end{array}$ & $\begin{array}{l}\text { O valor da pressão de ar esta diretamente ligada } \\
\text { com a variação de temperatura da parte inferior } \\
\text { das câmaras de combustão. }\end{array}$ \\
\hline 4 & $\begin{array}{l}\text { Teste de qualidade da } \\
\text { chama }\end{array}$ & Qualitativo & $\mathrm{x}$ & & & $\begin{array}{c}\text { Pressão } \\
\text { de Ar }\end{array}$ & $\begin{array}{l}\text { O valor da pressão de ar esta diretamente ligada } \\
\text { com a variação da qualidade de chama. }\end{array}$ \\
\hline 5 & $\begin{array}{l}\text { Controle dos Dampers do } \\
\text { 06VT09 e 06VT10 }\end{array}$ & Teste de correlação & $\mathrm{x}$ & & & $\begin{array}{l}\text { Vazão e } \\
\text { pressão } \\
\text { de ar }\end{array}$ & $\begin{array}{l}\text { Foi confirmada a curva de vazão dos ventiladores } \\
\text { através da variação da posição do damper, } \\
\text { pressão e vazão medido através de medidor } \\
\text { portátil PITOT }\end{array}$ \\
\hline
\end{tabular}

* Contribuição técnica ao 44ํ Seminário de Redução de Minério de Ferro e Matérias-primas, $15^{\circ}$ Simpósio Brasileiro de Minério de Ferro e $2^{\circ}$ Simpósio Brasileiro de Aglomeração de Minério de Ferro, 15 a 18 de setembro de 2014, Belo Horizonte, MG, Brasil. 
A avaliação feita em conjunto com engenheiros do forno através dos experimentos e dados levantados indica que as medidas não irão provocar nenhum efeito correlato. A tabela 5 mostra o plano de ação.

Tabela 5 - Plano de ação

\begin{tabular}{|c|c|c|c|c|c|c|}
\hline $\begin{array}{l}\text { Causas } \\
\text { Prioritárias } \\
\text { (X's) }\end{array}$ & $\begin{array}{l}\text { WHAT } \\
\text { Atividade } \\
\text { (o quê?) }\end{array}$ & $\begin{array}{c}\text { WHY } \\
\text { Objetivo } \\
\text { (por quê?) }\end{array}$ & $\begin{array}{l}\text { HOW } \\
\text { Procedimento } \\
\text { (como?) }\end{array}$ & $\begin{array}{l}\text { WHO } \\
\text { Responsá } \\
\text { vel } \\
\text { (quem?) }\end{array}$ & $\begin{array}{l}\text { WHERE } \\
\text { Local } \\
\text { (onde?) }\end{array}$ & $\begin{array}{l}\text { WHEN } \\
\text { Prazo } \\
\text { (quando?) }\end{array}$ \\
\hline $\begin{array}{l}\text { Falta de } \\
\text { controle dos } \\
\text { Dampers dos } \\
\text { VT's 06VT009 } \\
\text { e 06VT010 }\end{array}$ & $\begin{array}{l}\text { Instalar placa de } \\
\text { controle nos } \\
\text { Dampers }\end{array}$ & $\begin{array}{l}\text { Para possibilitar o } \\
\text { controle de abertura } \\
\text { dos Dampers }\end{array}$ & $\begin{array}{c}\text { Requisitando placa } \\
\text { junto ao suprimentos e } \\
\text { programando } \\
\text { instalação na parada } \\
\text { de usina }\end{array}$ & $\begin{array}{l}\text { Luiz } \\
\text { Claudio }\end{array}$ & $\begin{array}{l}\text { 06VT09 } \\
\text { 06VT10 }\end{array}$ & $\begin{array}{l}31 / 11 / 2013 \\
\text { Concluído }\end{array}$ \\
\hline $\begin{array}{l}\text { Instrumentos } \\
\text { de controle } \\
\text { descalibrados }\end{array}$ & $\begin{array}{c}\text { Calibrar } \\
\text { transmissor }\end{array}$ & $\begin{array}{l}\text { Para assegurar a } \\
\text { confiabilidade das } \\
\text { medições }\end{array}$ & $\begin{array}{c}\text { Calibrando o } \\
\text { transmissor de acordo } \\
\text { com o plano de } \\
\text { calibração }\end{array}$ & $\begin{array}{l}\text { Luiz } \\
\text { Claudio }\end{array}$ & $\begin{array}{l}\text { Ventiladores } \\
\text { 06VT09 } \\
\text { 06VT10 }\end{array}$ & $\begin{array}{l}31 / 10 / 2013 \\
\text { Concluído }\end{array}$ \\
\hline $\begin{array}{c}\text { Falta de } \\
\text { padronização } \\
\text { para o } \\
\text { controle do Ar }\end{array}$ & $\begin{array}{c}\text { Criar } \\
\text { procedimento } \\
\text { com as } \\
\text { padronizações } \\
\text { das pressões de } \\
\text { ar de } \\
\text { resfriamento das } \\
\text { camisas dos } \\
\text { queimadores }\end{array}$ & $\begin{array}{l}\text { Para que todos os } \\
\text { envolvidos executem a } \\
\text { tarefa de controle de ar } \\
\text { de forma padronizada }\end{array}$ & $\begin{array}{l}\text { Escrever o } \\
\text { procedimento e } \\
\text { padronização para o } \\
\text { controle de ar de } \\
\text { resfriamento das } \\
\text { camisas dos } \\
\text { queimadores }\end{array}$ & $\begin{array}{l}\text { Luiz } \\
\text { Claudio }\end{array}$ & GEU & $\begin{array}{l}31 / 12 / 2013 \\
\text { Concluído }\end{array}$ \\
\hline $\begin{array}{c}\text { Falta de } \\
\text { treinamento }\end{array}$ & $\begin{array}{l}\text { Treinar todos os } \\
\text { técnicos de sala } \\
\text { de controle da } \\
\text { pelotização da } \\
\text { Usina III }\end{array}$ & $\begin{array}{c}\text { Para capacitar os } \\
\text { envolvidos nos novos } \\
\text { procedimentos criados }\end{array}$ & $\begin{array}{l}\text { Após a criação do } \\
\text { procedimento e } \\
\text { padronização realizar } \\
\text { treinamento interno } \\
\text { com as partes } \\
\text { envolvidas. }\end{array}$ & $\begin{array}{l}\text { Luiz } \\
\text { Claudio }\end{array}$ & $\begin{array}{l}\text { Sala de } \\
\text { Reuniões } \\
\text { GEU }\end{array}$ & $\begin{array}{l}31 / 12 / 2013 \\
\text { Concluído }\end{array}$ \\
\hline $\begin{array}{l}\text { Erro de } \\
\text { indicação de } \\
\text { pressão na } \\
\text { tela do } \\
\text { operador }\end{array}$ & $\begin{array}{l}\text { Calibrar malha } \\
\text { de controle de } \\
\text { pressão }\end{array}$ & $\begin{array}{c}\text { Para garantir } \\
\text { identificação correta } \\
\text { da variável medida }\end{array}$ & $\begin{array}{l}\text { Calibrando o } \\
\text { transmissor de acordo } \\
\text { com o plano de } \\
\text { calibração }\end{array}$ & $\begin{array}{l}\text { Luiz } \\
\text { Claudio }\end{array}$ & $\begin{array}{l}\text { Ventiladores } \\
\text { 06VT09 } \\
\text { 06VT10 e } \\
\text { Automação }\end{array}$ & $\begin{array}{l}\text { 15/12/2013 } \\
\text { Concluído }\end{array}$ \\
\hline $\begin{array}{c}\text { Alterar a e } \\
\text { Especificação } \\
\text { técnica do } \\
\text { queimador }\end{array}$ & $\begin{array}{l}\text { Pressurizar a } \\
\text { camisa do } \\
\text { queimador sob } \\
\text { alta pressão e } \\
\text { baixar vazão }\end{array}$ & $\begin{array}{c}\text { Reduzir a vazão de Ar } \\
\text { de resfriamento da } \\
\text { camisa e garantir a } \\
\text { integridade mecânica } \\
\text { do queimador }\end{array}$ & $\begin{array}{c}\text { Modificar a camisa do } \\
\text { queimador }\end{array}$ & $\begin{array}{l}\text { Emerson } \\
\text { Caus }\end{array}$ & Forno 3 & $\begin{array}{l}10 / 09 / 2013 \\
\text { Cancelada }\end{array}$ \\
\hline
\end{tabular}

A ação de "pressurizar a camisa do queimador sob alta pressão e baixar vazão" foi cancelada uma vez que os testes não mostraram benefícios para a combustão. As demais ações foram executadas.

A figura 5 ilustra a mudança na camisa do queimador que resultou em má qualidade da chama. Devido a isso a ação foi cancelada. 

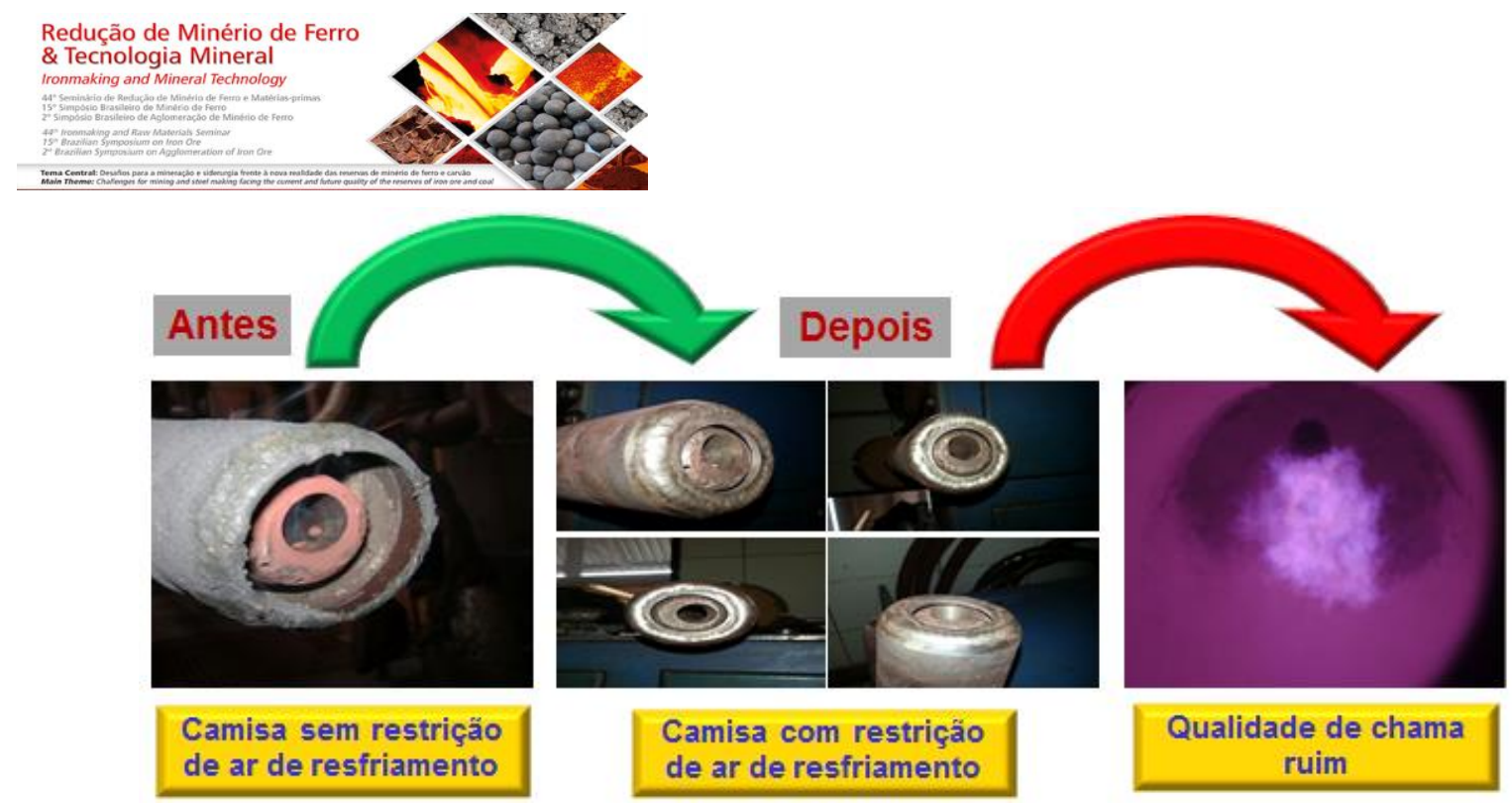

Figura 5 - Mudança na camisa do queimador resultando em má qualidade da chama.

Os experimentos industriais foram realizados em 8 queimadores e foram distribuídos entre o inicio, meio e fim da zona de queima. Observa-se uma tendência positiva na evolução da temperatura da parte superior da câmara de combustão dos queimadores analisados conforme a figura 6.
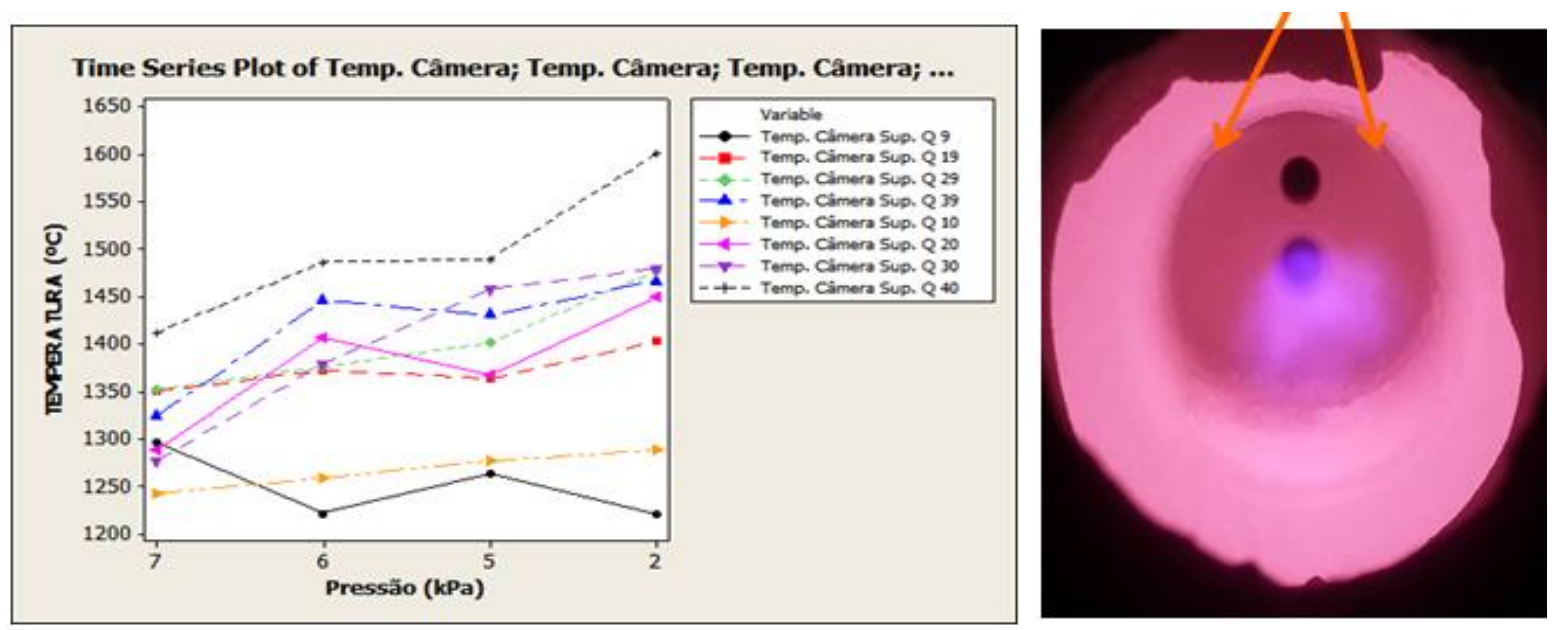

Figura 6 - Pontos de medição e gráfico de temperatura x pressão

Observa-se uma tendência também positiva na evolução da temperatura da parte inferior da câmara de combustão dos queimadores analisados conforme a figura 7.
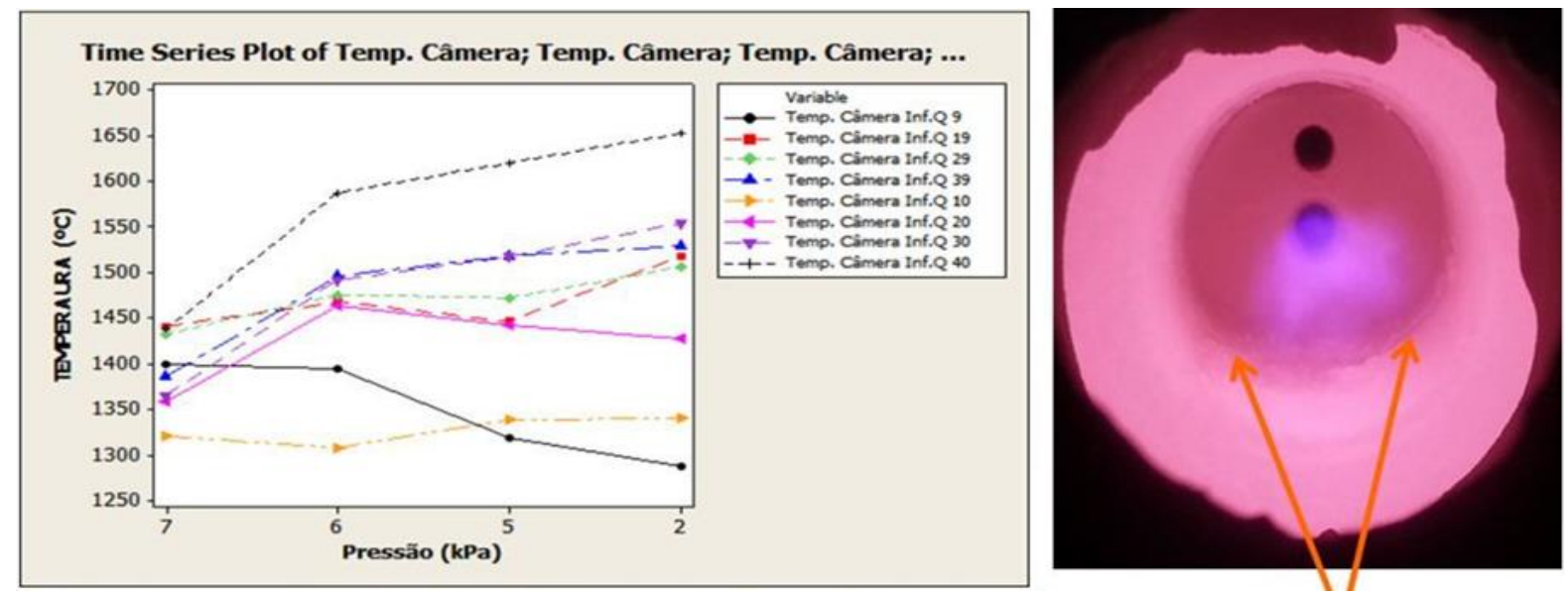

Figura 7 - Pontos de medição e gráfico de temperatura x pressão.

* Contribuição técnica ao 44 Seminário de Redução de Minério de Ferro e Matérias-primas, 15 Simpósio Brasileiro de Minério de Ferro e $2^{\circ}$ Simpósio Brasileiro de Aglomeração de Minério de Ferro, 15 a 18 de setembro de 2014, Belo Horizonte, MG, Brasil. 
Observa-se uma tendência positiva na evolução da temperatura na camisa dos queimadores analisados. Conforme Figura 8.

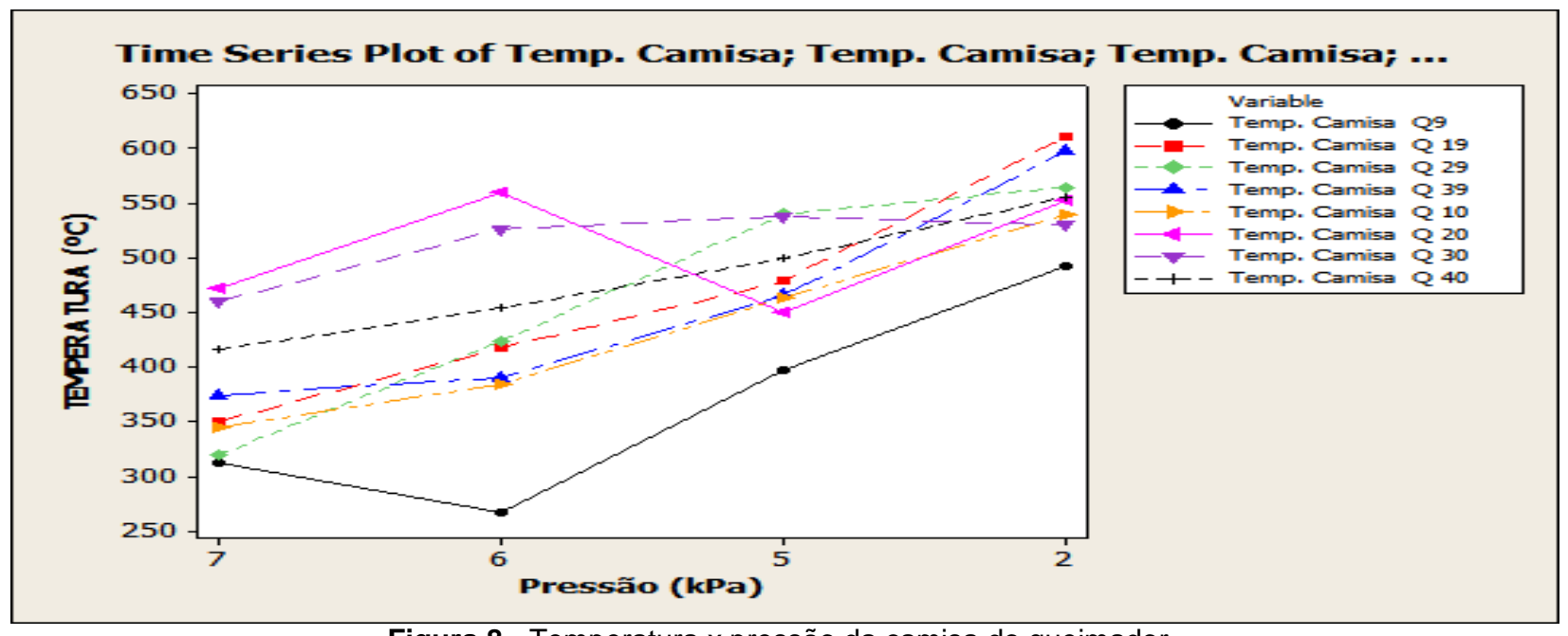

Figura 8 - Temperatura x pressão da camisa do queimador.

A qualidade da chama piora à medida que reduzimos a pressão de ar de resfriamento das camisas. Para a temperatura do refratário da parte superior e inferior e para a camisa a pressão tem uma relação direta, ou seja, à medida que reduzimos a pressão do ar, a temperatura aumenta. Esse efeito é ilustrado na figura 9.

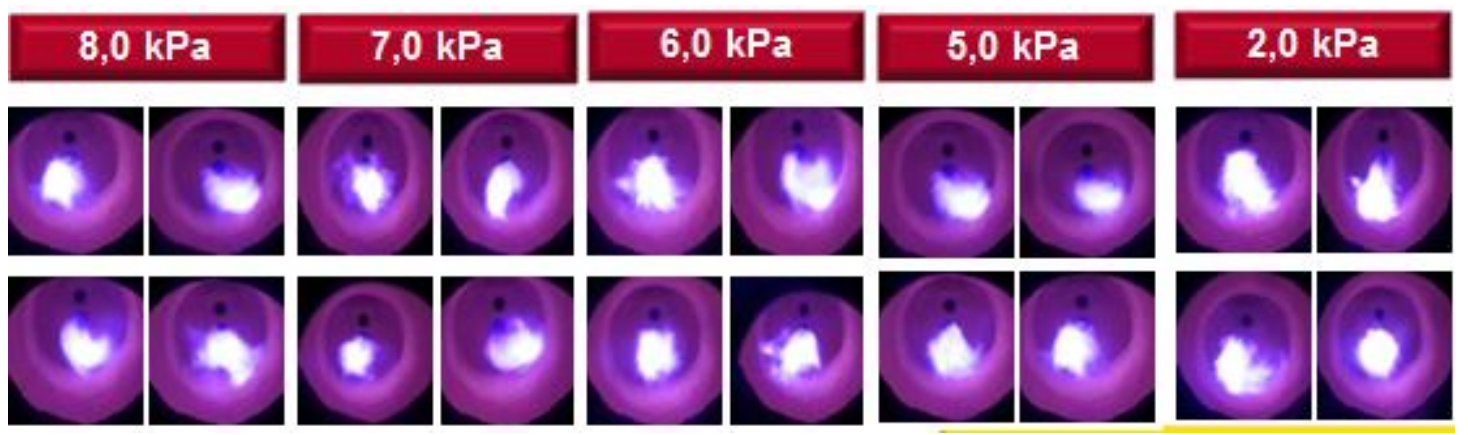

Figura 9 - Fotografias ilustrando a qualidade da chama.

Percebe-se que não existe variação significativa na qualidade da chama entre 5,0 e $8,0 \mathrm{kPa}$. Abaixo de $5,0 \mathrm{kPa}$ a qualidade da chama piora a medida que reduzimos a pressão de ar de resfriamento das camisas. Na figura 10 é ilustrado esse efeito.

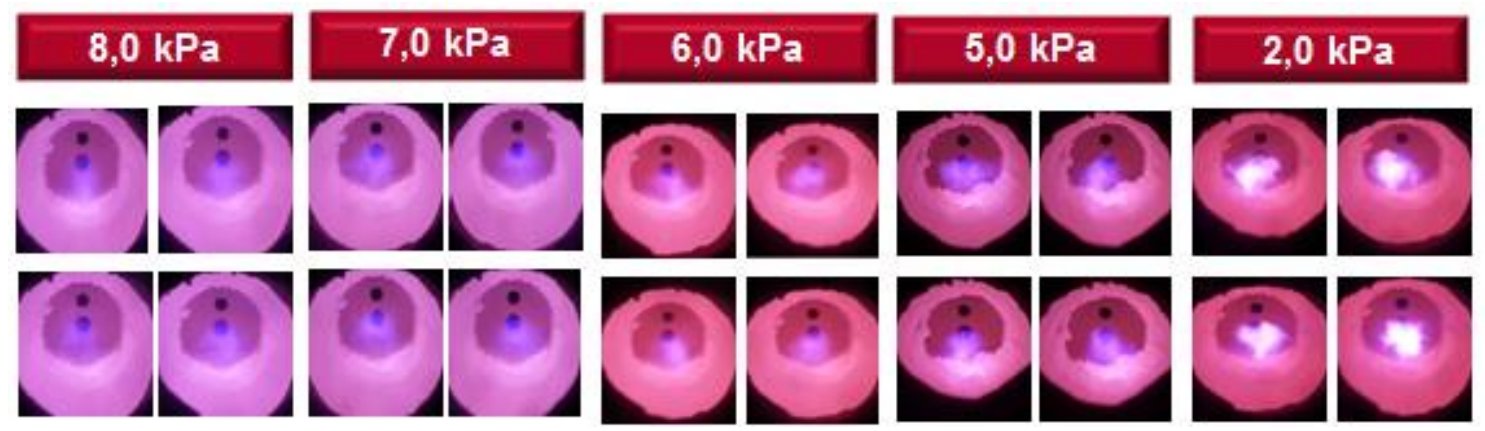

Figura 10 - Fotografias ilustrando a qualidade da chama.

Para a temperatura do refratário da parte superior e inferior a pressão tem uma relação direta, assim como para a temperatura da camisa como podemos ver na Figura 11.

* Contribuição técnica ao 44 Seminário de Redução de Minério de Ferro e Matérias-primas, 15 Simpósio Brasileiro de Minério de Ferro e $2^{\circ}$ Simpósio Brasileiro de Aglomeração de Minério de Ferro, 15 a 18 de setembro de 2014, Belo Horizonte, MG, Brasil. 

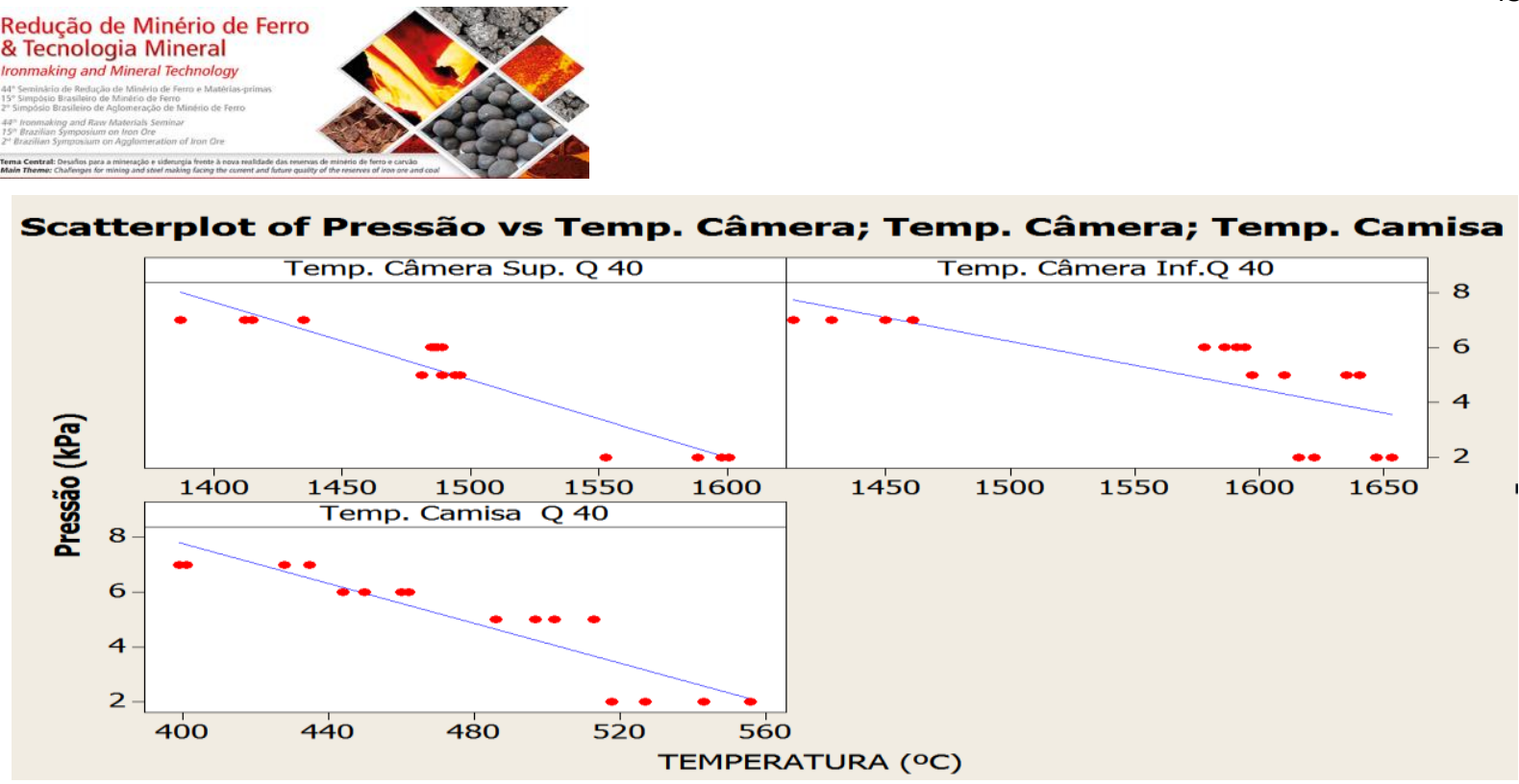

Figura 11 - Temperatura da câmara x pressão.

Com as ações realizadas no improve, foi possível alcançar a meta específica. A planilha nos mostra a média de pressão proposta e a média ponderada da pressão atingida por cada ventilador.

$\mathrm{Na}$ figura 12 podemos verificar a redução no valor médio de pressão de ar de resfriamento das camisas dos queimadores. Para confirmar a mudança no patamar de pressão foi utilizado o teste estatístico de comparação das amostras do baseline e do control.

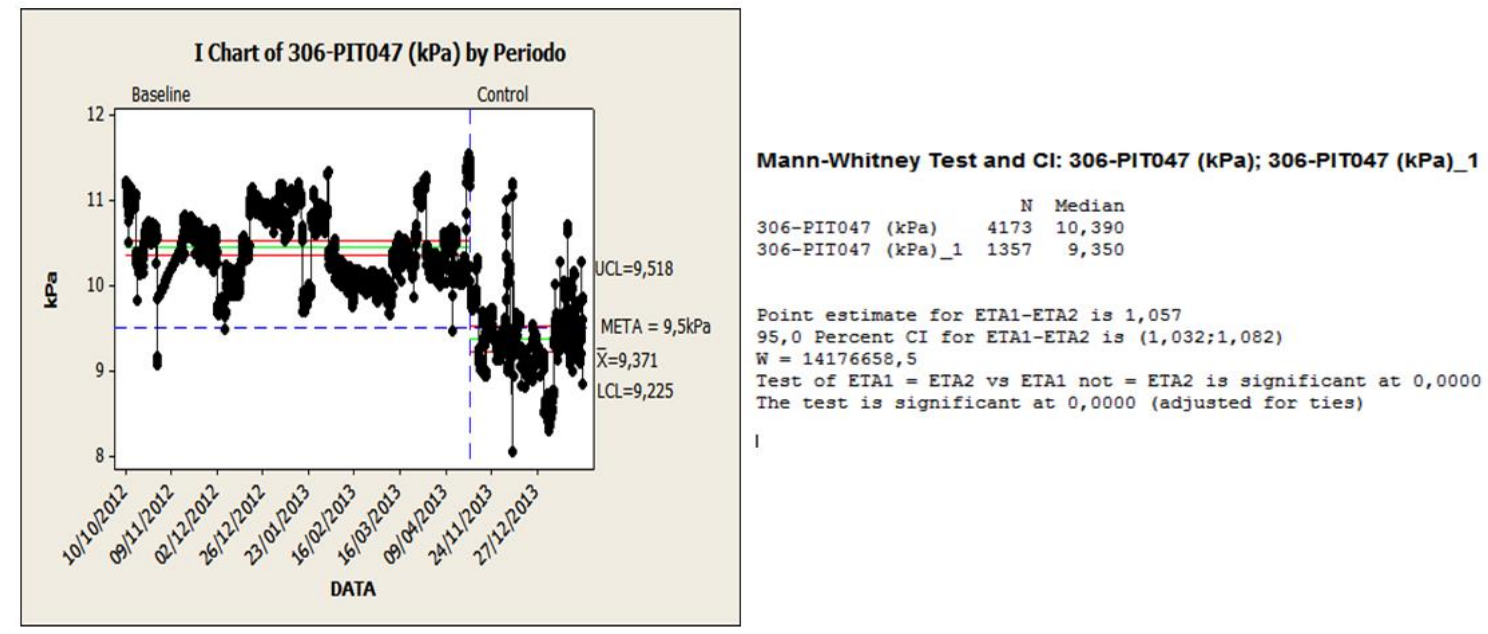

Figura 12 - Comparação das amostras do baseline e do control

$\mathrm{Na}$ figura 13 podemos verificar a redução no valor médio do calor perdido pelo sistema de combustão. Para confirmar a mudança no patamar de calor perdido foi utilizado o teste estático de comparação das amostras do baseline e do control.

* Contribuição técnica ao 44 Seminário de Redução de Minério de Ferro e Matérias-primas, $15^{\circ}$ Simpósio Brasileiro de Minério de Ferro e $2^{\circ}$ Simpósio Brasileiro de Aglomeração de Minério de Ferro, 15 a 18 de setembro de 2014, Belo Horizonte, MG, Brasil. 

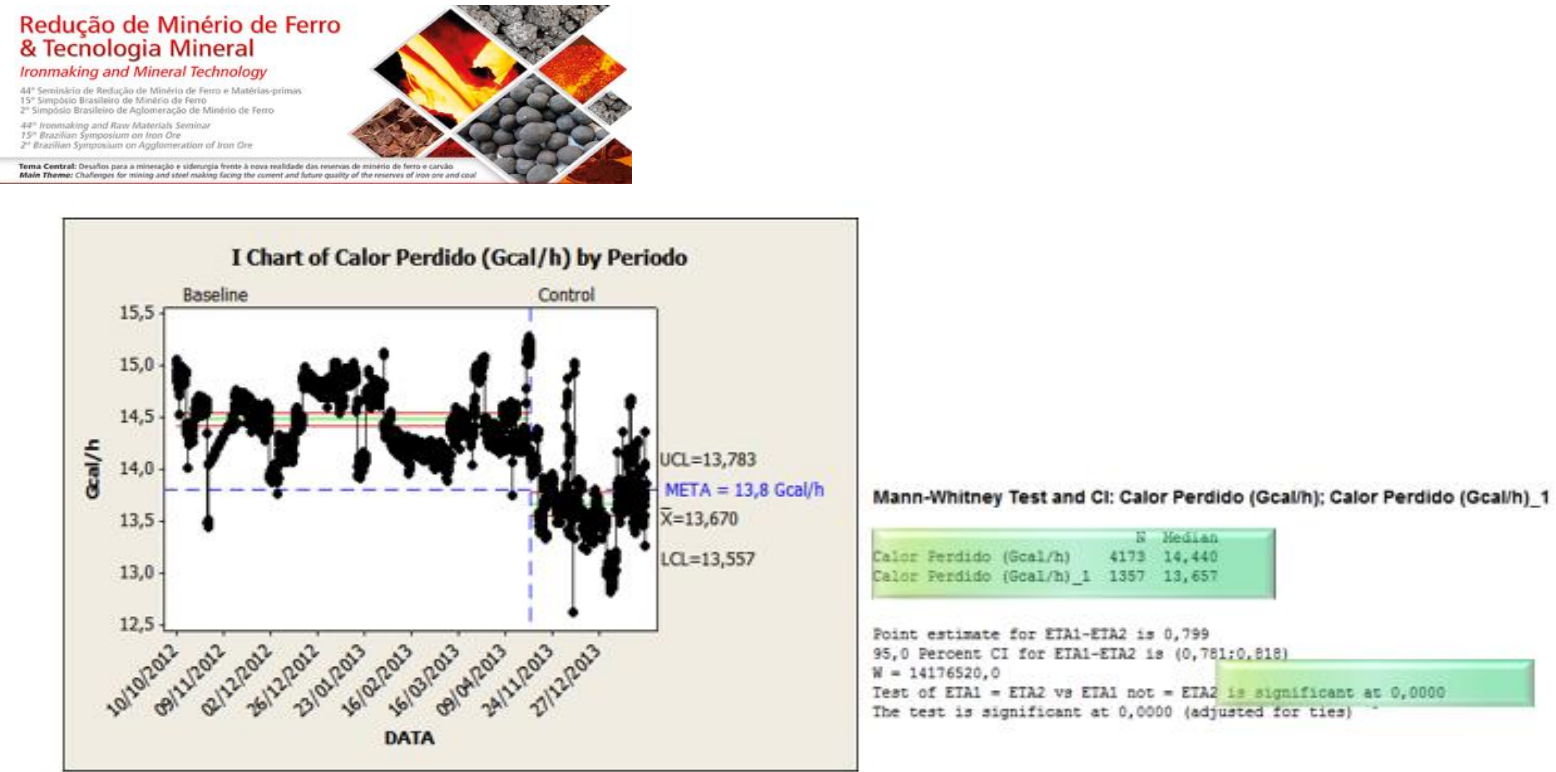

Figura 13 - Comparação das amostras do baseline e do control.

\section{CONCLUSÃO}

Foi criada uma lógica de abertura dos Dampers dos ventiladores de pressurização 06VT09 e 06VT10 para controlar a pressão de ar de resfriamento das camisas. A lógica de controle de pressão do ar de resfriamento das camisas dos queimadores segue de forma que o damper do ventilador que estiver em operação controle automaticamente a pressão corrigindo qualquer variação do processo instantaneamente independente da ação do operador. Além disso, foi estabelecido um procedimento para controle da pressão do ar de resfriamento das camisas, contendo os parâmetros críticos de ajuste.

Foi criado no PIMS um sistema de monitoramento do indicador através de telas que indicam os valores da pressão de ar de resfriamento das camisas bem como o volume de ar injetado ao forno através do sistema de combustão. Com bases nesses valores é possível calcular a perda de calor provocada pelo sistema. O OCAP orienta o Técnico de sala de controle quanto às ações a serem tomadas caso haja algum desvio do indicador. O projeto de redução das perdas térmicas foi realizado no forno da Usina 3 e poderá ser replicado para as usinas 1 e 2 com potenciais de ganho do mesmo patamar.

\section{BIBLIOGRAFIA}

1 Athayde M, Tavares RP, Nunes SF, Fonseca CM. Avaliação da distribuição de gases em forno de pelotização da Samarco Mineração através de CFD e validação experimental. In: 43ํㅗㄹ Seminário de Redução de Minério de Ferro e Matérias-Primas \& 14ํㅗimpósio Brasileiro de Minério de Ferro \& 1ํ Simpósio Brasileiro de Aglomeração de Minério de Ferro; 2013; Belo Horizonte, Brasil. São Paulo: ABM; 2013.

2 Athayde M, Tavares RP, Fonseca CM, Nunes SF, Costa CM, Cotta SVCL. Industrial Flow Distribution Improvement based on CFD Analysis in a Pelletizing Furnace at Samarco. In: 44ํㅗำ Seminário de Redução de Minério de Ferro e Matérias-Primas \& 15 Simpósio Brasileiro de Minério de Ferro \& $2^{\circ}$ Simpósio Brasileiro de Aglomeração de Minério de Ferro; 2014; Belo Horizonte, Brasil. São Paulo: ABM; 2014.

* Contribuição técnica ao 44 Seminário de Redução de Minério de Ferro e Matérias-primas, $15^{\circ}$ Simpósio Brasileiro de Minério de Ferro e $2^{\circ}$ Simpósio Brasileiro de Aglomeração de Minério de Ferro, 15 a 18 de setembro de 2014, Belo Horizonte, MG, Brasil. 